\title{
ROBOTIC PROCESS AUTOMATION FOR RECRUITMENT PROCESS
}

\author{
Dr Nishad Nawaz \\ Assistant Professor, Department of Business Management, College of Business \\ Administration, Kingdom University, Bahrain.
}

\begin{abstract}
Purpose - The aim of the paper to review the Robotic process automation in the recruitment process and its practical implications. This paper discussed possible applications for the recruitment industry caused due to the adoption of Robotic process automation in the recruitment process.

Design/methodology/approach - This paper is structured by the independent academician, who have reviewed of the latest articles, research papers, reports and other relevant literature and synthesized their views in the process of presenting the paper.

Findings - This paper offers technology development in the field of hiring industry. The RPA for managing the hiring process and also discussed possible applications and usage of $R P A$ in the recruitment industry.

Originality/value - The paper explains the role of technology and impact of RPA on the recruitment industry as well as clients in the Industry and the highlighted Inputs for successful integration and possible applications for recruitment industry.

Article classification - Viewpoint.

Keywords: Robotic process automation, recruitment industry.

Cite this Article Dr Nishad Nawaz, Robotic Process Automation for Recruitment Process, International Journal of Advanced Research in Engineering and Technology, 10(2), 2019, pp. 608-611.

http://iaeme.com/Home/issue/IJARET?Volume=10\&Issue $=2$
\end{abstract}

\section{INTRODUCTION}

In the $21^{\text {st }}$ century has introduced many technologies, the way organizations are doing their business, human resources do their tasks as well as the public daily life is going to be drastically assisted by new hardware, software technologies along with smart devices. The human being life style has been changed due to the multinational culture, collaborations, along with new technologies such as Big Data, Internet of Things, Deep Learning, Machine Learning, Artificial Intelligence and other associated technologies, besides, Robotic process automation applications are spotted, and it is now beginning to impact HR process. (Madakam, M. Holmukhe and Kumar Jaiswal, 2019). 
Robotic process automation (RPA) is a new emerging technology in recruitment Industry and which will help various Industries progress and compete to stay on top of their business game. The most of the HR departments of any business is responsible for many tasks along the hire-to-retire process, in this there are many activities are repetitive, efficiency, applicant engagement, applicant experience, time consuming and some of the work still dependent on manual based process to help employees accomplish their work done. This process depends on the labor force process is costly and not productive and sometimes will leads to the higher rate of errors and even compromise compliance level.

Robotic process automation is a technology embedded software that utilizes the robots to replace human actions for performing administrative tasks. RPA software integrate with existing functions \& tools to handle basic tasks through automation and such reduce the time consume, cost burden on the process, addition to complete individual tasks.

The next section explains the various technologies of Robotic process automation, which are the inputs for successful integration of Robotic process automation, finally future applications for recruitment Industry from the Robotic process automation.

\section{ROBOTIC PROCESS AUTOMATION TECHNOLOGY FOR RECRUITMENT.}

RPA reduces lot of manual based work to speed-up business growth by facilitating real-time communication leading to find right candidate with job matching and will assess to how to apply for specific position. RPA will also help recruiters to eliminate, which is not related to the advertised position. RPA bots communicate to the candidate of their rejection, why it is rejected and facilitate the feedback concerning on deficiency in skills, qualifications and providing future requirements of company and RPA enabled technology provide notifications, schedule of the interview and also communicate which skills are looking for future recruitment by the organization.

The RPA useful in sending automated communications for the applicant through email and text, however it also collecting, processing \& organizing of information regarding candidate, helpful to create database of the candidate for future use. This will lead to the enhancement of the quality in recruitment process by shortlisting the applicants and to process the data, to give right information to have right decision in selecting a person based on applicant's team work abilities, knowledge, attributes \& soft skills.

The nature of RPA searching across platforms for candidates automatically responding to potential candidates and sending out customized request to candidates. As per the Ben Slater (2019) it will be very easy to increase candidate experience via type form, beamery surveys and also useful for efficiency \& data entry. Automated eradicate unbiased items, increased privacy and sensitive data it can leads to the better decisions on recruitment process. RPA empowered the process of onboarding such as offer letter administration process, the new email account, adding new hire in the existing list, creating new telephone connection, new card process and information regarding login codes to the new joiner.

RPA enabled algorithms can mimic human brain activity to recognize their values, behavior, skills shortage gap of the candidate standing in front of them. It will stimulate human conversation available $24 / 7$ and construct strong candidate relationship management (CRM) with recruitment agencies to improve their quality, decision making, security and to prepare future talent pool.

RPA technology enabled chatbots assistant real-time communications, leverage sentiments, engagement with candidate. Candidate interact with empowered RPA technology through text messaging, email, social media, messaging apps like WhatsApp, slack, skype and ATS etc. For 
effectiveness of recruitment process, the RPA technology offer details of the candidate (i.e. cv, cover letter, contact information, experience, education and skills, reference checklist, drivers license), FAQ, regarding advertisement of the job and schedule of the interview to the recruiter.

\section{INPUTS FOR SUCCESSFUL INTEGRATION OF ROBOTIC PROCESS AUTOMATION IN THE RECRUITMENT PROCESS.}

Human and robots work together, the robots will take care of copying, repetitive data and other related tasks and at the same time human have an opportunity to concentrate in complex issues and to make quality work and decisions.

The talent pool embedded with diverse teams, so recruiters required to understand recruitment need, identification of talent community, recruitment marketing strategies, employee turnover. RPA should enable empowerment and instant gratification of the candidates. For successful integration in the recruitment process. It is very essential to have of time of hire should have hiring \& cost effective. RPA need to reach fast to the perspective candidate. RPA integration required to take care of the communications, information of candidate, sourcing \& screening, automation of simple questions \& instructions.

The RPA should be user friendly and for both sides of the recruiters and candidates. The systems should offer a great efficiency, boost the applicant engagement and experience. RPA technology scrutiny increase the best fit of the candidate hiring with-out compromising on the quality.

\section{POSSIBLE APPLICATIONS FOR RECRUITMENT INDUSTRY FROM THE ROBOTIC PROCESS AUTOMATION ADOPTION.}

(Lecaillon, Halpin and Hennebert, 2018) Deloitte's human capital trends report expressing that 47 percent HR leaders said that most of the organizations already in involved in automation, but only 24 percent are using AI \& robotics in their daily or routines works and another study of LinkedIn survey stated that 35 percent of hiring managers said that by 2020, RPA will be list in the top in recruitment industry.

RPA is changing the nature of competition in the digital economy and recruitment industry as well by impacting all of the accuracy, saving potentials, duration, productivity, reliability and retention. RPA is significant force on recruitment industry, as it changes the strategic direction for the future recruitment Industry. Recruitment industry controlling by using of RPA technology control expenditure on talent acquisition for the clients and it will boost the profitability and quality decision making.

the recruitment agencies have to develop business model, where agency will work for development and to improve the candidate relation management or engagement. The model should contain following new skills such as social intelligence, relationship building, influencing, negotiation, collaborations, critical thinking, and emotional intelligence, asking questions, finding information, data analysis and judgment with quality decision.

\section{CONCLUSION}

The RPA technology is very important tool for streamlining the recruitment and hiring process. The automation in the recruitment enabled the talent acquisition and hiring professional to have a right decision faster by increasing candidate efficiency across the hiring process. Therefore, RPA technology have a significant impact on an organization to find the right balance between talent and human interaction. 


\section{REFERENCES}

[1] Lecaillon, B., Halpin, L. and Hennebert, N. Getting Started Agenda Here with you today RPA Today-RPA tomorrow 2 RPA what are the challenges and insights from the expert. (2018)

[2] J. Krishnaraj, K. Sangeetha, M.V. Babu Tanneru, VVS Harnadh Prasad and M. Vishnu Vardhan. A Mecanum Wheel Based Robot Platform for Warehouse Automation. International Journal of Mechanical Engineering and Technology, 8(7), 2017, pp. 181-189.

[3] Madakam, S., M. Holmukhe, R. and Kumar Jaiswal, D. 'the Future Digital Work Force: Robotic Process Automation (RPA)', Journal of Information Systems and Technology Management, 16, (2019) pp. 1-16. Doi: 10.4301/s1807-1775201916001.

[4] Snehal K.Paliwal, Mrs. Shaila P. Kharde, Robinson, Reagan Nnabio and Kpabep, Charity M., A Review On Data Acquisition and Control System for Industrial Automation Application. International Journal of Electronics and Communication Engineering \& Technology, 6(7), 2015, pp. 26-30.

[5] Ben, S.L.A.T.E.R. Candidate experience recruiting with robots: is automation a dirty word? [Online]. [18 March 2019]. Available from: https://beamery.com/blog/recruitmentautomation.

[6] Arvind N. Nakiya, Mahesh A. Makwana and Ramesh R. Gajera, An External Plunge Grinding Machine with Control Panel Automation Technique Based on Mitsubishi PLC System, International Journal of Electrical Engineering and Technology (IJEET), Volume 4, Issue 4, July-August (2013), pp. 197-204.

[7] LinkedIn 2018 report highlights top global trends in recruiting. [Online]. [15 March 2019]. Available from: https://news.linkedin.com/2018/1/global-recruiting-trends-2018.

[8] Arka Sain, Janardan Dattani and Dhara M Mehta, Design and Implementation of Wireless Control of Pick and Place Robotic Arm, International Journal of Advanced Research in Engineering and Technology, 9(3), 2018, pp 276-283.

[9] Deloitte insights. 2018. The rise of social enterprise, 2018 Deloitte global human capital trends. [Online]. [10 March 2019]. Available from: https://www2.deloitte.com/content/dam/Deloitte/at/Documents/human-capital/at-2018deloitte-human-capital-trends.pdf

[10] Varalakshmi B D, Abhilasha Pachauri, Thriveni J, Venugopal K R and Patnaik L M, Mems Sensors Controlled Haptic Forefinger Robotic Aid, International Journal of Advanced Research in Engineering and Technology (IJARET), Volume 5, Issue 10, October (2014), pp. 45-54. 